\title{
Identificação de Potenciais Reservatórios Utilizando a Perfilagem Geofísica de Poços
}

\author{
Michael de Souza Santos \& Carlos André Maximiano da Silva, UFES
}

Copyright 2014, SBGf - Sociedade Brasileira de Geofísica

Este texto foi preparado para a apresentação no VI Simpósio Brasileiro de Geofísica Porto Alegre, 14 a 16 de outubro de 2014. Seu conteúdo foi revisado pelo Comitê Técnico do VI SimBGf, mas não necessariamente representa a opinião da SBGf ou de seus associados. É proibida a reprodução total ou parcial deste material para propósitos comerciais sem prévia autorização da SBGf.

\section{Resumo}

A aplicação geológica de perfis geofísicos tem como principal objetivo proporcionar uma melhor competência petrofísica dos reservatórios. As características essenciais dos reservatórios são: porosidade, litologia, argilosidade, permeabilidade, densidade e a presença de fluidos. Sendo que essas características podem ser inferidas indiretamente a partir de mensurações feitas através de sensores que percorrem o poço.

Com a crescente atividade industrial, forçou as companhias de perfilagem a desenvolverem um maior número de sensores e de melhores métodos telemétricos, aparecendo mais tarde, combinações de sensores, montados em uma única ferramenta, reduzindo o tempo das operações de perfilagem.

\section{Introdução}

O primeiro perfil geofísico (natureza elétrica) foi realizado em um poço comandado pelos irmãos Conrad e Marcel Schlumberger aplicando a eletrorresistividade em um poço Francês. Não demorando muito para perceberem o quanto era importante esta ferramenta, uma vez que as argilas normalmente apresentam uma baixa resistividade. As rochas permoporosas são condutivas se saturadas com água salgada, moderadamente resistiva se o fluído de saturação for água doce e muito resistiva se o fluído for óleo. Podendo haver a separação das rochas de natureza selante das de natureza reservatório e informações sobre o tipo de fluído nos poros poderiam ser deduzidas.

A procura pela existência de novas jazidas de petróleo tem feito com que técnicas já conhecidas venham ganhando uma importância maior para que se tenha um menor custo da operação de exploração com resultados mais exatos, ou seja, menos incertezas e mais certezas.

$\mathrm{Na}$ indústria do petróleo, os métodos de avaliação exploratória em poço aberto, ou seja, sem revestimento baseia-se, principalmente, na Perfilagem Geofísica e nos testes de formação. Um poço pode ser completado sem ter sido executado um só teste de formação. Todavia, jamais será completado ou revestido sem que tenha sido perfilado anteriormente (a poço aberto). Para se ter uma noção da magnitude do risco, que é muito bem percebido na indústria, a cada dez poços perfurados não mais que três deles têm acumulações comerciais.

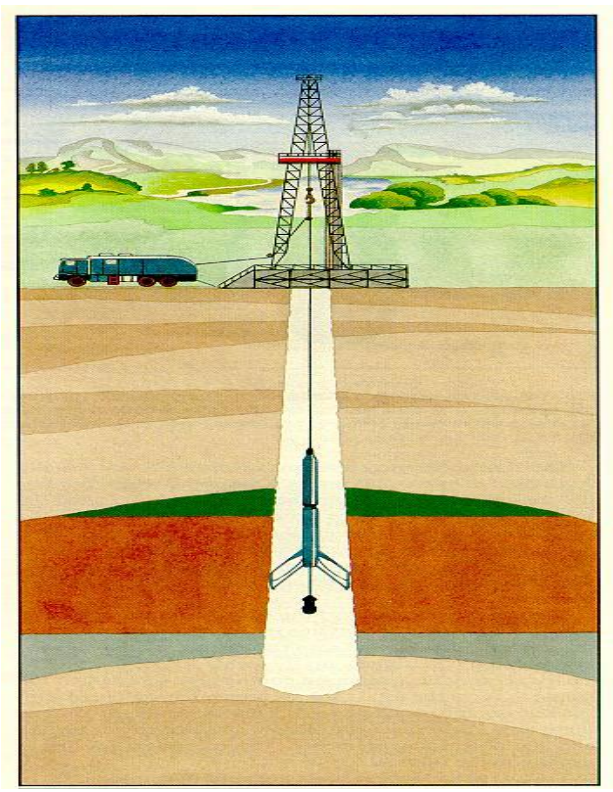

Figura 1 - Representação esquemática de uma descida de uma ferramenta de perfilagem (modificado de Ellis, 1987)

\section{Metodologia/ Problema Investigado}

A metodologia aplicada no seguinte trabalho foi 0 carregamento de perfis geofísicos de poços obtidos pelo campo escola de Namorado. Para a realização deste trabalho, os arquivos de três poços, NA002, RJS042 e NA0012 foram carregados no software Matlab R2013b para a geração dos perfis.

Os dados dos arquivos localizam-se no formato LAS, que é formado por um cabeçalho (contendo informações sobre o poço e os perfis medidos) e por colunas numéricas.

As principais ferramentas utilizadas foram; Raios Gama (GR), Neutrônico; Indução; Caliper e Densidade e a interpretação deste estudo foi baseado nos registros dessas curvas. O perfil de Raios Gama mede a radioatividade natural das rochas. Trata- se de um dos melhores indicadores litológicos através do registro dos pulsos (fótons) emitidos pela radiação natural liberada pelos elementos urânio, tório e potássio (isótopo K40), existente em qualquer rocha, ígnea, metamórfica ou sedimentar (Nery, 2000). Em formações sedimentares as medidas refletem o conteúdo de argila nas rochas sedimentares (Luiz \& Silva, 1983). O perfil Neutrônico 
(NPHI) é utilizado para a estimativa de porosidade, litologia e detecção de hidrocarbonetos leves ou gás. O perfil de indução (ILD) mede a condutividade elétrica da formação por meio da propagação de ondas eletromagnéticas. $\mathrm{O}$ Cáliper mede o diâmetro do poço e verifica se existe algum desmoronamento ou estrangulamento da parede do poço. O perfil de Densidade (RHOB) além de medir a densidade das camadas, permite $o$ cálculo da porosidade e a identificação das zonas de gás.

Tabela 1. Exemplo de arquivos LAS.

\begin{tabular}{cccccc} 
Depth & GR & NPHI & RHOB & CALIPER & ILD \\
\hline 3000.1952 & 584.688 & 189.453 & 25.234 & 85.391 & 25.767 \\
3000.3476 & 613.125 & 192.017 & 25.259 & 85.352 & 25.630 \\
3000.5000 & 637.344 & 195.435 & 25.327 & 85.371 & 25.708 \\
3000.6524 & 662.734 & 198.608 & 25.361 & 85.391 & 25.771 \\
3000.8048 & 667.344 & 196.289 & 25.293 & 85.391 & 25.679 \\
3000.9572 & 638.828 & 186.890 & 25.161 & 85.371 & 25.493 \\
3001.1096 & 596.016 & 178.711 & 25.083 & 85.332 & 25.400 \\
3001.2620 & 561.406 & 177.002 & 25.146 & 85.312 & 25.469 \\
3001.4144 & 545.312 & 178.467 & 25.283 & 85.312 & 25.713
\end{tabular}

A primeira linha contém a identificação de cada curva e, nas colunas, os valores amostrados a cada $20 \mathrm{~cm}$ de poço.

\section{Resultados}

A geofísica de poços (Perfilagem) é de grande importância na localização de possíveis zonas produtoras e na elaboração de um projeto de completação competente para as possíveis zonas de interesse. Foram analisados 9 intervalos dos poços, NA002, RJS042 e NA0012 figuras, 2, 3, 4 respectivamente.

\section{Analises do Resultados}

A tabela 2, que apresenta os perfis para cada poço estudado, foi obtida a partir da interpretação e conhecimento da aplicação geológica de perfis geofísicos.

No poço NA002 foram identificados 3 intervalos, aonde No perfil GR é possível distinguir três corpos arenosos, os 2 primeiros corpos, pode ser interpretado como arenito argiloso, enquanto que o corpo inferior é um arenito bastante limpo. A resistividade ILD nos intervalos A e B são altas atestando a possível presença de Hidrocarbonetos, enquanto que o intervalo $C$ apresenta uma baixa resistividade atestando a presença de água. $O$ contraste do perfil de Densidade (22\%, porosidade alta) com o Neutrônico $\left(2,2 \mathrm{~g} / \mathrm{m}^{3}\right.$, densidade baixa) no intervalo $A$, indica uma zona de gás, seguida por uma zona de óleo e finalizando como uma zona de água no intervalo.

Fazendo a mesma interpretação para os dois poços restantes, encontramos no poço RJS0042 uma zona possivelmente de óleo seguida por outra de água. E no poço NA0012 foi encontrado quatro intervalos, aonde possivelmente apresenta duas zonas de água, uma de óleo e uma de gás o mesmo contraste do perfil de densidade com o Neutrônico visto no primeiro poço.

Tabela 2. Resultados obtidos para cada poço estudado.

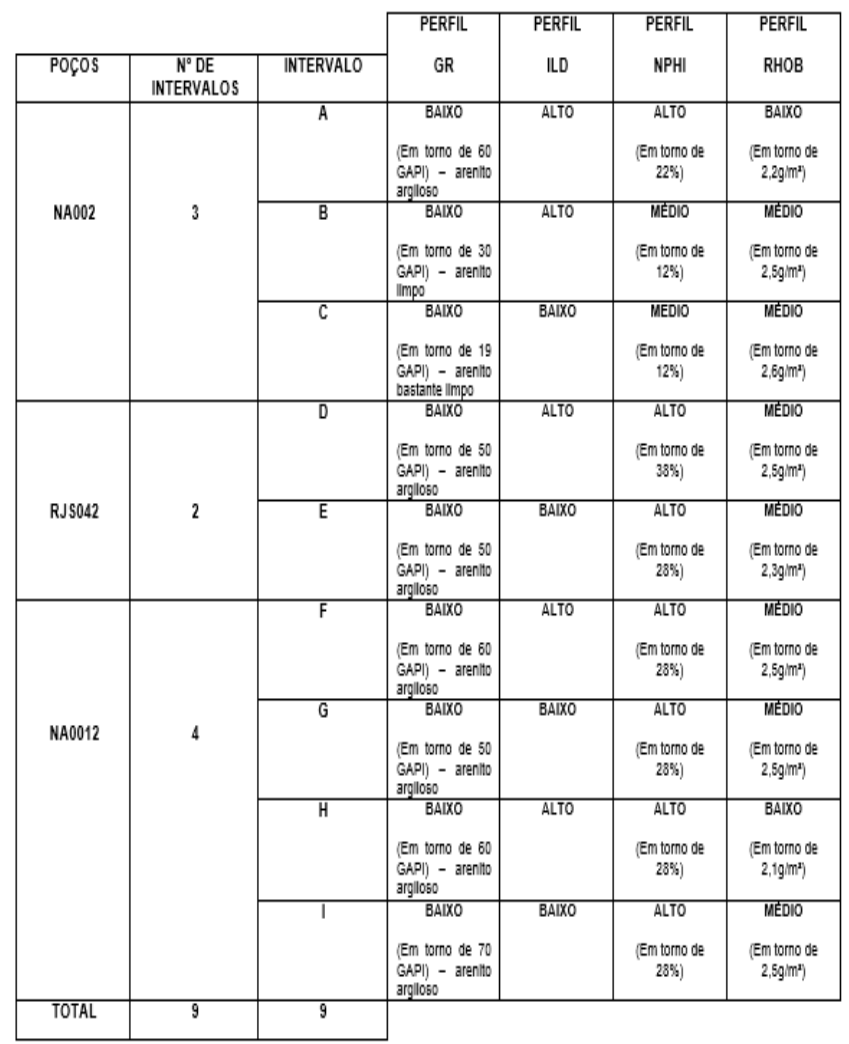

\section{Discussão e Conclusões}

Neste trabalho, demonstrou-se a aplicação da análise conjunta dos perfis de Raio Gama, porosidade, Densidade e Resistividade para a interpretação geológica das áreas estudadas. Essa interpretação indicou a existência de formações onde estas, seriam reservatórios de alta produtividade.

No primeiro poço NA002 onde se encontra uma capa formada por gás e logo após a existência de uma jazida comercial de petróleo seguida por um aquífero. Importante ressaltar que esse reservatório no momento de entrar em produção, teria ao seu favor, dois mecanismos de produção; os mecanismos de capa de gás e influxo de água. Já o poço RJS0042 teria o mecanismo de influxo de água observado na figura 2.

No terceiro poço NA0012 pela zona de óleo estar localizada na parte superior da coluna, uma operação de 
Completação seria mais simples comparada com os outros poços.

É importante ressaltar que a metodologia testada neste trabalho não substitui a experiência dos profissionais envolvidos nesse projeto. Entretanto a interpretação dos dados dos perfis analisados permite a otimização de um projeto e a montagem de uma estratégia de perfuração.

\section{Agradecimentos}

Os autores agradecem à ANP pela cessão dos dados da Bacia de Campos e a Universidade Federal do Espírito Santo - UFES, pela infra-estrutura laboratorial.

\section{Referências}

Ellis, D.V., 1987. Well Logging For Earth Scientists, Elsevier, $532 p$

Faustino, L., H., C., 2007, Simulação de perfis Sônico do Campo de Namorado Através da Técnica de Defuzificação Paramétrica, 43p.

Leite, M. V. C., 2007. Simulação do Perfil Sônico para Poços do Campo de Namorado Utilizando a lógica Fuzzy, $138 p$.

Lima, K.T. P. 2002. Métodos Acústicos de Perfilagem.

Magalhães, A. C.G.T. 2004. Aplicação do método fuzzy para reconhecimento de padrões em perfis de poços do Campo de Namorado- Bacia de Campos, RJ, 94p. Monografia Curso de Geologia - UFRJ.

Menezes, S. X. \&Adams, T., 1988. Ocorrência de Resistividades Anômolas no Campo de Namorado.v.2, p. 359-366.

Milani, E.J \& Zalán, P. V., 2000, Petróleo na Margem Continental Brasileira, Revista Brasileira de Geofísica, Vol. 18, p 352-396.

Mimbela, F. R. R., 2005. Modelo Fuzzy para Predição Conjunta de Porosidade e Permeabilidade Via Perfis Convencionais de Poço do Campo de Namorado - Bacia de Campos, R.J, 136p.

Miranda, A. I. F. 2004. Imageamento da Porosidade Através de Perfis geofísico de Poço, 58p.Tese de Doutorado UFPA.

Nery, G. G., 2004. Perfilagem Geofísica, Notas de Aulas, UFBA,50p.

Nery, G. G. Perfilagem Geofisíca em Poço Aberto: Fundamentos Básicos Com Ênfase Em Petróleo. Rio de Janeiro.
Oliveira, J. K. de, 2005. Efeito da Porosidade Efetiva e da argilosidade nas Velocidades de Ondas P no Arenito Namorado, 49p.

SILVA, R. B. G. 1983. Estudo hidroquímico e isotópico das águas subterrâneas do aqüífero Botucatu no Estado de São Paulo. - IG-USP 133p. (Tese de Doutoramento). 


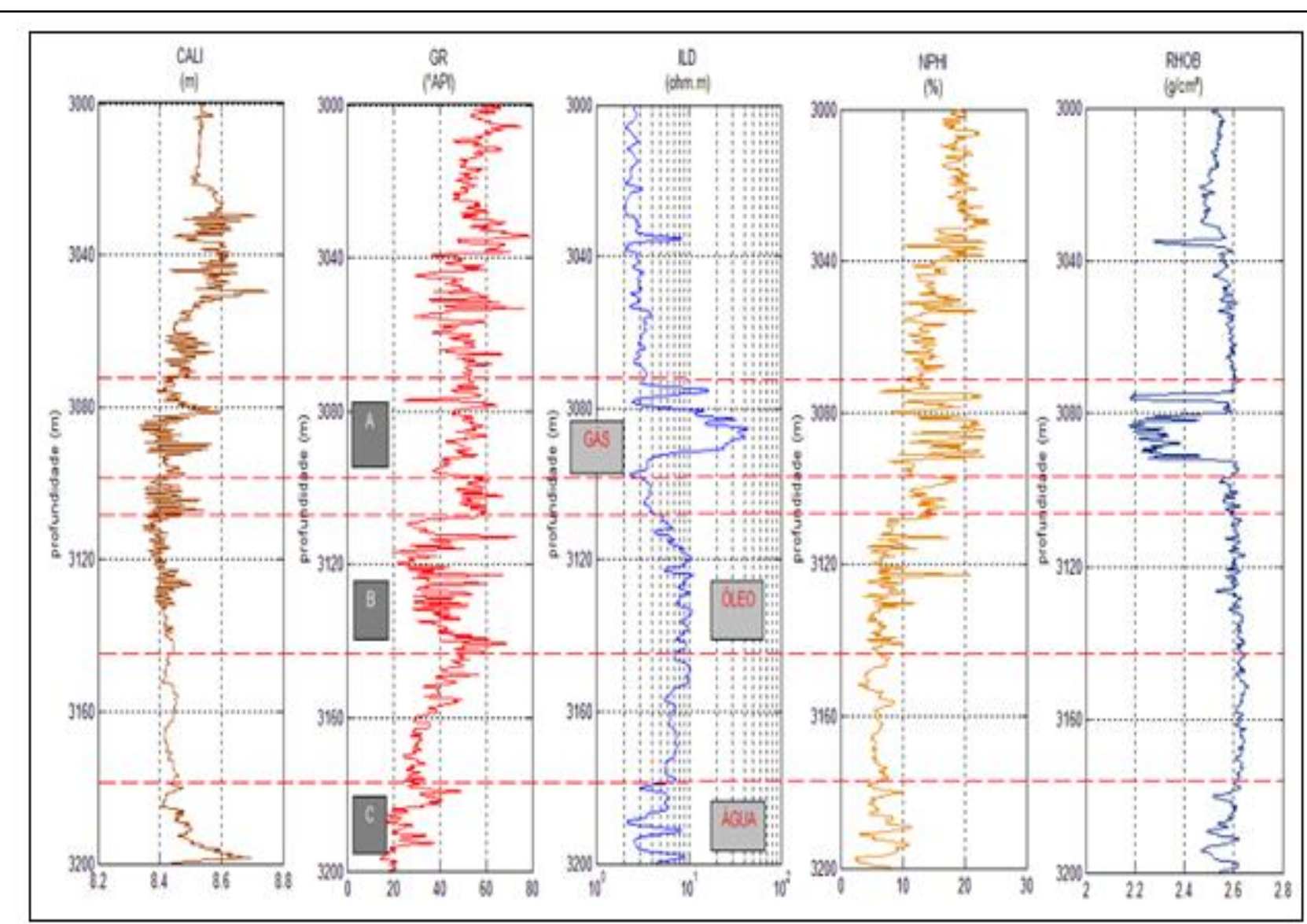

Figura 2 - Curvas produzidas a partir dos dados do poçoNA002 carregados para o software MatLab. 


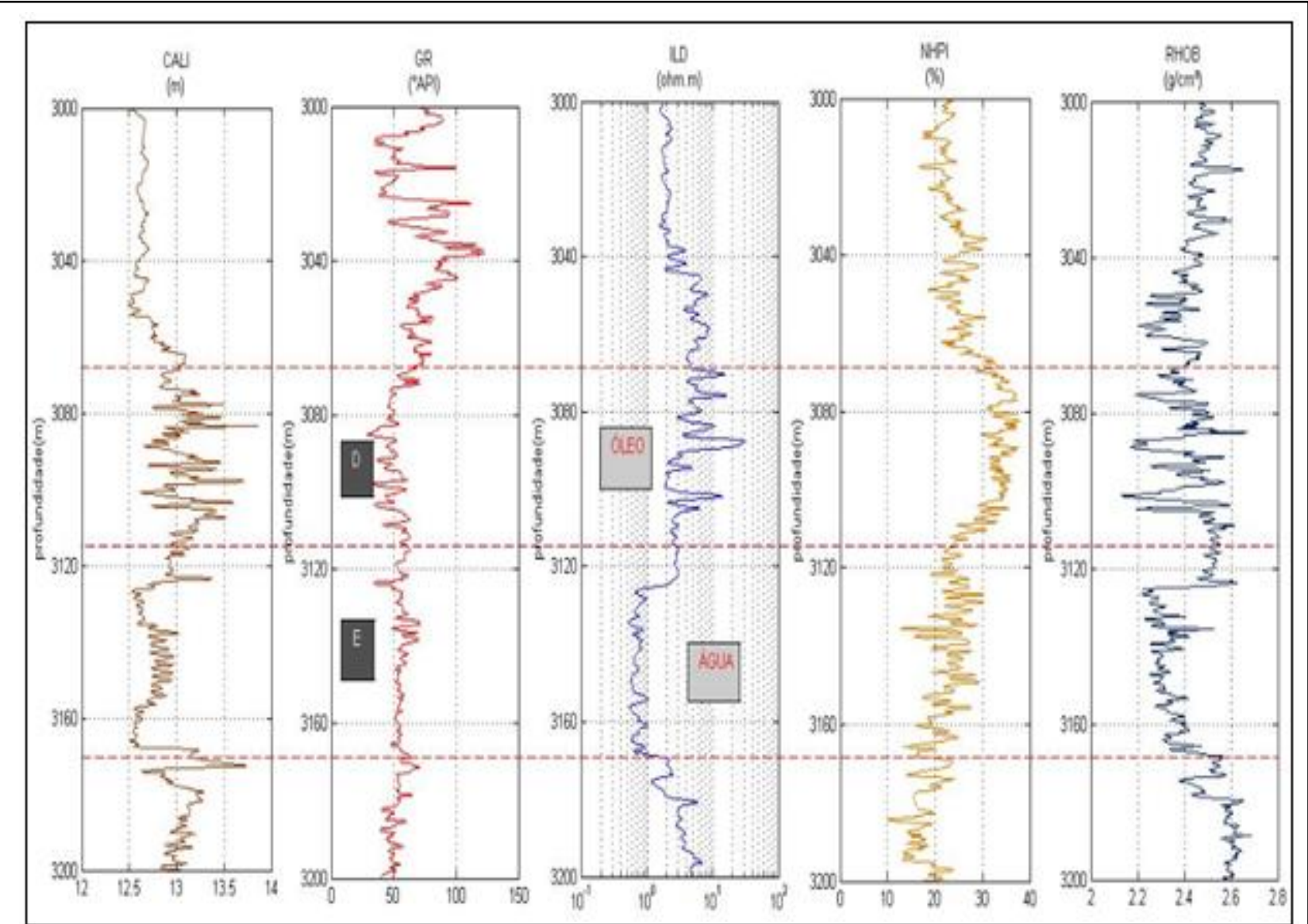

Figura 3- Curvas produzidas a partir dos dados do poço RJS0042 carregados para o software MatLab. 


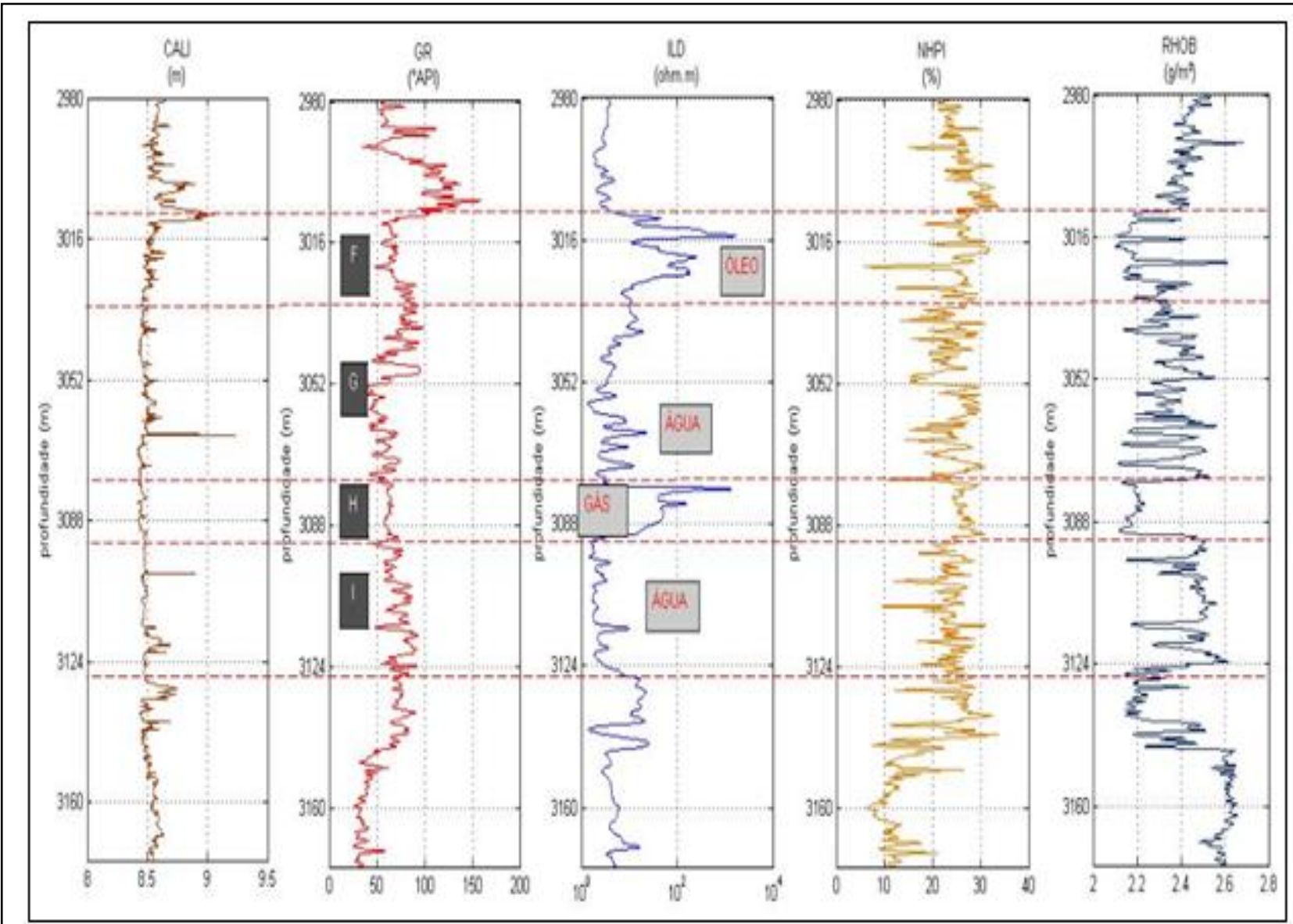

Figura 4 - Curvas produzidas a partir dos dados do poço NA0012 carregados para o software MatLab. 